\title{
Virtual occlusal record: a literature review about the digital method
}

\author{
Registros oclusais virtuais: uma revisão da literatura sobre o método digital \\ Registros oclusales virtuales: una revisión de la literatura sobre el método digital
}

Received: 10/07/2021 | Reviewed: 10/14/2021 | Accept: 10/22/2021| Published: 10/24/2021

\author{
Mariana Elias Queiroz \\ ORCID: https://orcid.org/0000-0002-1036-2617 \\ São Paulo State University, Brazil \\ E-mail: mariana.equeiroz@gmail.com \\ Eduardo Dallazen \\ ORCID: https://orcid.org/0000-0002-7994-5634 \\ São Paulo State University, Brazil \\ E-mail: dallazen.d@gmail.com \\ Mariana Sati Cantalejo Tsutsumi \\ ORCID: https://orcid.org/0000-0001-7104-712X \\ São Paulo State University, Brazil \\ E-mail: marianasctsutsumi@gmail.com \\ Ana Teresa Maluly-Proni \\ ORCID: https://orcid.org/0000-0002-3303-3058 \\ São Paulo State University, Brazil \\ E-mail: atmaluly@gmail.com \\ Eduardo Passos Rocha \\ ORCID: https://orcid.org/0000-0002-0157-3690 \\ São Paulo State University, Brazil \\ E-mail: 1rocha.eduardo@gmail.com \\ Wirley Gonçalves Assunção \\ ORCID: https://orcid.org/0000-0002-8903-0737 \\ São Paulo State University, Brazil \\ E-mail: wirley.assuncao@unesp.br \\ Paulo Henrique dos Santos \\ ORCID: https://orcid.org/0000-0002-4100-5153 \\ São Paulo State University, Brazil \\ E-mail: paulo.santos@unesp.br
}

\begin{abstract}
To produce prostheses through the digital flow, it is essential to transfer the correct patient's interocclusal relationship to the digital software program, enabling the articulation of virtual models. Therefore, the aim of this study was to carry out a narrative literature review to describe and discuss aspects related to the virtual occlusal record realization, as well as its precision and accuracy in different clinical situations. Searches for scientific publications were performed in different databases and only articles in English related to the topic were selected. Different methods for the alignment of virtual models are described in the literature, the main one being the scanning of the patient in occlusion, usually in a position of maximum intercuspation. However, this technique may demonstrate disagreement with the patient's actual occlusal relationship due to several factors, and therefore studies were carried out to verify the precision and accuracy of these records. Most studies use plaster models and industrial scanner to capture the record, with few studies performed with intraoral scanner in patients. Despite the various scanner systems available and the different ways of evaluating them, in general, the studies show an adequate precision and accuracy of virtual occlusal records of dentate models. However, the absence of dental elements is related to the lower accuracy of these records, it being necessary to establish an appropriate method of scanning for these clinical situations.
\end{abstract}

Keywords: Dental occlusion; Computer-aided-design; Dental prosthesis.

\section{Resumo}

Para produção de próteses por meio do fluxo digital é fundamental a transferência da correta relação interoclusal do paciente para o programa de software digital, possibilitando a articulação dos modelos virtuais. Portanto, o objetivo desse estudo foi realizar uma revisão de literatura narrativa para descrever e discutir aspectos relacionados à realização do registro oclusal virtual, bem como à sua precisão e acurácia diante das diferentes situações clínicas. As buscas por publicações científicas foram realizadas em diferentes bases de dados e apenas artigos em inglês relacionados ao tema foram selecionados. Diferentes métodos para o alinhamento de modelos virtuais são descritos na literatura, sendo o escaneamento do paciente em oclusão, geralmente em posição de máxima intercuspidação, o principal. Porém, essa técnica pode demonstrar alterações em relação à oclusão real do paciente devido a diversos 
fatores, e por isso, estudos foram realizados para verificar a precisão e acurácia desses registros. Os estudos em sua grande maioria utilizam modelos de gesso e scanner industrial para captura do registro, havendo poucos trabalhos realizados com scanner intraoral em pacientes. Apesar dos diversos sistemas de scanner disponíveis e das diferentes formas de avaliação dos mesmos, de maneira geral os trabalhos mostram uma precisão e acurácia adequada dos registros oclusais virtuais de modelos dentados. Entretanto, a ausência de elementos dentais, está relacionada à menor acurácia desses registros, sendo necessário estabelecer um método apropriado de escaneamento para essas situações clínicas.

Palavras-chave: Oclusão dentária; Desenho assistido por computador; Prótese dentária.

\section{Resumen}

Para la producción de prótesis mediante flujo digital, es fundamental trasladar la correcta relación interoclusal del paciente al programa informático digital, posibilitando la articulación de modelos virtuales. Por tanto, el objetivo de este estudio fue realizar una revisión narrativa de la literatura para describir y discutir aspectos relacionados con la realización del registro oclusal virtual, así como su precisión y exactitud en diferentes situaciones clínicas. Se realizaron búsquedas de publicaciones científicas en diferentes bases de datos y solo se seleccionaron artículos en inglés relacionados con el tema. En la literatura se describen diferentes métodos para la alineación de modelos virtuales, siendo el principal el escaneo del paciente en oclusión, generalmente en una posición de máxima intercuspidación. Sin embargo, esta técnica puede demostrar desacuerdo con la oclusión real del paciente debido a varios factores, por lo que se llevaron a cabo estudios para verificar la precisión y exactitud de estos registros. La mayoría de los estudios utilizan modelos de yeso y escáner industrial para capturar el registro, y pocos estudios se realizan con escáner intraoral en pacientes. A pesar de los diversos sistemas de escáner disponibles y las diferentes formas de evaluarlos, en general, los trabajos muestran una adecuada precisión y exactitud de registros oclusales virtuales de modelos dentados. Sin embargo, la ausencia de elementos dentales está relacionada con la menor precisión de estos registros, siendo necesario establecer un método de escaneo adecuado para estas situaciones clínicas.

Palabras clave: Oclusión dental; Diseño asistido por computadora; Prótesis dental.

\section{Introduction}

Conventional techniques to make dental prostheses have been widely successfully used by dental surgeons and dental technicians (Russo et al., 2019). These techniques consist in molding the area to be restored, using the most suitable material for each type of prosthesis, followed by the obtainment of casts for manual manufacture of prostheses in a laboratory environment (Nagarkar et al., 2018). However, this process is composed by some critical steps that depend on the knowledge and skill of the operator (Wong et al., 2018). Some errors can occur, such as dimensional changes due to the molding material used properties, tearing of the material during tray removal and bubbles formation in the model that are capable of interfering in the treatment success (Fang et al., 2019; Russo et al., 2019 Wong et al., 2018). Therefore, conventional prostheses production techniques require knowledge and experience of the operator for the correct application of materials and procedures execution, thus minimizing possible changes that may impair the final work (Russo et al., 2019).

The use of a digital workflow by means of digital scanner and computer-aided-design and computer-aidedmanufacturing (CAD-CAM) has become an alternative to conventional techniques for making dental prostheses (Sailer et al., 2019). CAD-CAM is a technology that allows the design and fabrication of objects and has been used in dentistry since 1980 for the production of inlays, onlays, single and multiple fixed prostheses, and implants prostheses (Ahlholm et al., 2018; Bostford et al., 2019, Nagarkar et al., 2018). This system is divided into three main steps. The first step consists in collecting data from the region of interest through intraoral or laboratory scanner, transforming the information into virtual models. In the second stage, a software is responsible for the design of the restoration on the virtual model. Finally, a computerized device is used to make the restoration using a block of solid material or by the additive technique (Alghazzawi, 2016). The accuracy of the restorations performed by this system depends on some factors, including the optical technology used by scanner and the algorithm associated with the digital system (Ahlholm et al., 2018; Sailer et al., 2019).

The digital workflow in dentistry offers some advantages such as greater patient comfort, since oral scanning eliminates the need for conventional impressions. In addition, it discards the use of plaster models, allows better 
communication with the dental technician, and presents greater time efficiency compared to conventional techniques (Botsford et al., 2019; Mangano et al., 2017). Currently, there are several companies that offer different scanner and CAD-CAM systems on the market. However, they are still systems that are constantly evolving and have some limitations, the most common are the learning curve required to adopt scanner systems, the difficulty of some systems in detecting deep marginal lines of prepared teeth and the high cost of acquiring the equipment (Iwauchi et al., 2021; Mangano et al., 2017; Park et al., 2018).

Some studies have been carried out in order to compare the accuracy of models and prostheses performed by the digital method and the conventional method (Ender et al., 2016; Ender et al., 2016). When compared with the conventional method for impressions of quadrants, the digital method demonstrates a satisfactory precision (Ender et al., 2016; Sailer et al., 2019). On the other hand, when compared regarding the accuracy of impressions of complete arches, it seems that the digital method is less accurate than the conventional method, with greater distortion in the region of the molars (Ender et al., 2016; Sailer et al., 2019). Studies showed that the use of a digital flow for making single crowns or up to three elements prostheses supported by a tooth or implant has shown good results in terms of precision and is a good alternative to the use of conventional techniques (Batson et al., 2014; Russo et al., 2019).

Regardless of the type of prosthesis to be elaborated, the correct record of the patient's occlusal relationship is essential. To make restorations with adequate morphology and to reduce the amount of adjustments in the prosthesis installation, it is essential to transfer this relationship accurately to the digital software program, thus allowing a correct articulation between the digital models (Ren et al., 2020). Some methods for the virtual record of the patient's occlusal relationship have been described and investigated in the literature (Ren et al., 2020; Alghazzawi, 2016). Considering the importance of the occlusal record for the process of making dental prostheses, the aim of this study was to explore, through literature review, the aspects related to the realization of virtual occlusal record, as well as its precision and accuracy in different clinical situations.

\section{Methodology}

This work is a narrative bibliographic review, which aims to describe and discuss the virtual occlusal record from a theoretical point of view, according to the authors' interpretation and critical analysis (Rother, 2007). Searches for scientific publications were performed in Cochrane Library, Google Scholar, National Library of Medicine (PUBMED) and Scientific Electronic Library Online (SCIELO) databases, using the descriptors Virtual Occlusal Record, Computer-Aided-Design, Dental Prosthesis, Intraoral Scanner, Accuracy and Digital Models. Only articles in English and related to the topics were included.

\section{Literature Review}

Establishing the correct interocclusal relationship between virtual models is a challenging process (Sweeney et al., 2015). Conventional plaster models can be manually articulated in maximum intercuspation position (MIP), or, in situations where there are missing elements and occlusal contacts, materials for occlusal registration can be used, thus enabling the correct establishment of intermaxillary relationships (Sweeney et al., 2015). However, when it comes to the articulation of virtual models, they depend on occlusal records captured by the scanner, tools that guide the positioning of the intermaxillary relationship or an experienced software operator. Some software for viewing digital models don't have collision restrictions, which indicates that two separate 3D images, the maxillary and mandibular models, can continue to move through each other even after contact between them (Sweeney et al., 2015). 
Some methods for aligning complete dentated virtual models, with or without virtual interocclusal records, are described in the literature. One of them is the alignment of the models by the visual method, however, it is a technique with uncertain precision that demands a lot of time (DeLong et al., 2002; Sweeney et al., 2015). The most common method is the use of bite scanning function of scanner systems, in which the buccal face of the teeth of the upper and lower arch in intercuspation are scanned, usually in the position of maximum intercuspation (MIP), and through the best fit algorithm, the alignment of the virtual models is done (Abdulateef et al., 2019; Seo et al., 2019; Sweeney et al., 2015; Wong et al., 2018). Each scanner has a specific corresponding software, which requires different regions for the occlusal record scans (Solaberrieta et al., 2016). Some software require scanning the buccal posterior teeth in intercuspation, while others also require scanning the anterior region. There are still those that use scanning of only one segment in occlusion (Solaberrieta et al., 2016).

Another technique is the scanning of materials used for interocclusal record. In this technique the software identifies points in the model that are combined with points in the record and, in this way, the best fit algorithm is able to align the upper and lower virtual models (Sweeney et al., 2015). One study showed that, among the different materials used for interocclusal registration, polyvinylsiloxane had better accuracy for articulating digital models (Sweeney et al., 2015).

There are few studies related to virtual interocclusal record and scanning of edentulous arches for making complete dentures (Fang et al., 2019). In this clinical scenario, it is necessary to reproduce the patient's mucosa, covering mobile areas and smooth surface textures completely covered by saliva, factors that become obstacles through scanner record (Fang et al., 2019). In addition, the absence of teeth requires the search for a method for scanning the correct occlusal vertical dimension (OVD). To overcome these limitations, a technique using an instrument for vestibular mucosa removal is described in the literature. This device is used along with an occlusal record in polyvinylsiloxane to maintain the position of the patient in OVD for scanning the maxillomandibular relationship in totally edentulous patients. Thus, it is possible to reproduce edentulous digital maxillary models with maxillomandibular relationships through direct prints and virtual records of the occlusion relationship through an intraoral scanner (Fang et al., 2019).

The interocclusal records used to assemble the virtual models may demonstrate non-compliance with the patient's actual occlusion, which can lead to inaccuracy in the articulation of the virtual models and, consequently, the production of prostheses requiring many adjustments (Seo et al., 2019). This inaccuracy may be related to some factors, including the type of scanner and software used, the deficient scanning technique and also the size of the patient's arch (Seo et al., 2019; Solaberrieta et al., 2016). Therefore, studies have been carried out to verify both the precision and accuracy of these records and to elucidate the best way to transfer the patient's occlusal relationship to virtual models (Seo et al., 2019). It is important to emphasize that precision and accuracy, despite being important parameters, are different factors. Accuracy refers to the agreement of a result with a reference value, while precision is related to the repeatability or reproducibility of a given procedure (Botsford et al., 2019; Iwauchi et al., 2021).

To analyze the precision and accuracy of virtual occlusal records, some methodologies are described in the literature, which seek to compare the reference occlusal relationship with the relationship between virtual models. One of these methods compares the contacts found in the mouth or in physical models with the contacts found in the articulation of the digital models after scanning (Botsford et al., 2019; DeLong et al., 2002; DeLong et al., 2007; Edher et al., 2018; Seo et al., 2019; Solaberrieta et al., 2016; Solaberrieta et al., 2015). For this, an image of the contacts evidenced by means of articulating paper or by transillumination of silicone records is obtained. This image is superimposed on the occlusal contacts found in the digital software after articulating the virtual models. The accuracy of the virtual occlusal record is verified through the difference in quantity, intensity, extension or location of virtual contacts compared to those found clinically or in physical models. Seeking to verify the accuracy of the virtual occlusal contacts, a current technique allows scanning the contacts in the mouth evidenced with articulating paper and comparing them with the contacts observed by the perforation of the $3 \mathrm{D}$ meshes which represent 
the intersection points between the upper and lower virtual arches (Seo et al., 2019). This method also allows correcting the alignment of virtual models according to the actual interocclusal contacts, but it is only applicable to color intraoral scanners (Seo et al., 2019).

Another method to assess the precision and accuracy of the transference of maxillo-mandibular relationship to digital environment is by measuring the distance between pre-established points in physical models (Iwaki et al., 2013; Ren et al., 2020; Wong et al., 2018). For this, interarch markers are used, which serve as a reference for manual and digital measurements. Another form of evaluation is through the superposition of meshes of the virtual models, which, through color maps, offer data referring to the 3D distortion between the models according to the occlusal relationship (Park et al., 2018; Iwauchi et al., 2021). As an additional technique to the superposition of the digital models, from cross-sections it is possible to verify linear distances (2D) between the meshes of the virtual models (Park et al., 2018; Iwauchi et al., 2021).

An initial study (DeLong et al., 2007) demonstrated that the interocclusal contacts verified in fully dentate virtual models presented accuracy when compared to those visualized in non-virtual models evidenced through the use of articulating paper and transillumination. Solaberrieta E. et al. (Solaberrieta et al., 2015) used three different software to compare occlusal contacts obtained in articulated plaster models and virtual models obtained by scanning. The contacts of the plaster models evidenced with articulating paper were compared to those of the virtual models obtained through a digital scanner by overlaying in the software. Virtual occlusal record proved to be an appropriate procedure for positioning the mandibular model in relation to the maxilla. Occlusal contacts changed by software when the same virtual models and occlusal records were compared. The authors emphasize the importance of knowing the deviation of the best fit tool or algorithm of each software.

Considering that different softwares require scanning of different regions for the virtual occlusal record, a study (Edher et al., 2018) evaluated whether the use of different arch locations for virtual interocclusal records affects the alignment of the models. In addition, it assessed whether quadrant or full-arch scanning affects the articulation of virtual models, using interocclusal recordings through an intraoral scanner. For scanning full arches, multiple virtual interocclusal records reduce the "tilt effect" present when these registrations are made in just a few specific locations. However, when the software does not allow multiple records, it is recommended to do the interocclusal registration closer to the area of interest. In these cases, anterior canine-to-canine records are more accurate in reproducing general occlusal contacts, compared to single lateral records. In addition, quadrant scanning reproduces with greater sensitivity and accuracy the interocclusal relationship, being more indicated in cases of prostheses or single restorations (Edher et al., 2018).

When there is a lack of contact between some elements of the arches, whether due to preparation for restorations or absence of dental elements, the accuracy of the virtual records may be affected. Iwaki Y. et al (Iwaki et al., 2013) verified that in the presence of single or multiple preparations in posterior regions, discrepancies on the contralateral side may occur in the virtual occlusal record, and they are higher than those found in conventional records. Nevertheless, when considering changes in horizontal rotations between models, which are critical for the interocclusal relationship, the digital method presents better accuracy results compared to the conventional method (Iwaki et al., 2013). In situations where teeth are absent, the occlusal alignment process of digital models can become doubtful (Ren et al., 2020). When analyzing digital occlusal records of models representing some edentulous situations, through manual and digital measurements of distances between interarch markers, Ren S. et al. (Ren et al., 2020) observed that the extension and location of edentulous areas affected their accuracy. The absence of only one posterior element was not able to affect the accuracy of the record, but extensive unilateral and bilateral edentulous spaces with three or more teeth absent in the anterior or posterior region affected its accuracy.

There are a variety of intraoral scanner systems available on the market. Each manufacturer has a software with different error correction algorithms, interpretation of the occlusal surface, in addition to requiring different ways of buccal interocclusal record. Among the most studied systems are iTero (Align Technology Inc., Santa Clara, California), Trios (2nd 
generation, 3Shape dental systems, Copenhagen, Denmark), CEREC Omnicam (Sirona Dental System), True Definition (3M, Minnesota, USA ) and CS3500 or CS3600 (Carestream dental, Sydney, Australia) (Wong et al., 2018; Park et al., 2018). Some studies (Wong et al., 2018; Park et al., 2018) were carried out with physical models comparing the accuracy of the virtual interocclusal record of these systems using different methodologies. When compared by measuring the distance between interarch markers, it was observed that there is a difference in the accuracy of the scanner models, the Trios Color scanner showed better precision comparing the distances of the virtual models with the plaster models and presented superior results to the True Definition and CEREC scanners (Wong et al., 2018). When using superimposition as a 3D analysis method, the CEREC scanner showed smaller deviations in relation to the CS3500, Trios, iTero and True Definition models. However, when performing 2D analyzes using the cross-section method of the virtual models, the iTero scanner showed smaller deviations, not presenting any difference to the CEREC scanner (Park et al., 2018).

The assessment of accuracy and precision of virtual interocclusal records is not only performed by scanning physical models, but also from intraoral scanning. A study using the CS3600 intraoral scanner (Carestream dental, Sydney, Australia) showed that the size and location of the occlusal contacts were accurate when comparing two scans of this system, exhibiting difference only in the intensity of these contacts (Botsford et al., 2019). Another study compared the discrepancies of the intraoral scans, using the Trios and True Definition scanners, through the conventional method by scanning plaster models using the 3D Laser Scanner (D900, 3Shape A/S). The same showed that intraoral scanners had similar results and smaller discrepancies compared to the conventional technique (Iwauchi et al., 2021).

\section{Discussion}

Most CAD CAM systems require virtual occlusal records to locate the virtual mandibular model in relation to the maxilla. However, studies on this procedure are still needed, since there are few studies evaluating the accuracy and applicability of the techniques and systems available, and most of them are in vitro studies (DeLong et al., 2002; Solaberrieta et al., 2015; Solaberrieta et al., 2016, Wong et al., 2018).

Each type (intraoral and laboratory) and trademark of scanner requires a specific technique of interocclusal record (Park et al., 2018). Scanning the buccal surface of teeth in occlusion, usually in the MIP position, is the most described method and the one with more data about its accuracy in the literature. According to some in vitro studies, this method has good reproducibility (Iwaki et al., 2013; Solaberrieta et al., 2015). However, most of these studies use a plaster model and industrial scanner to capture the record, with few in vivo studies on this technique (Solaberrieta et al., 2015, Iwaki et al., 2013). To verify precision and the accuracy of this method, further clinical studies with intraoral scanner in the oral environment are needed, thus introducing variables such as patient movements and saliva, which can influence this record (Ren et al., 2020).

When comparing different commercial brands of scanner available, possible reasons for the difference between the systems are related to the effect of different matching algorithms for each one, the cumulative effect of image captures, and the image post-processing for each system (Wong et al., 2018). When compared to each other, the studies showed divergent results in relation to the accuracy data for the same brand of scanner (Wong et al., 2018; Park et al., 2018). This difference can be justified due to the fact that the studies used different methodologies, making the comparison of results inconvenient.

Although it has been shown in an article that polyvinylsiloxane is the best material to be used for transferring the occlusal relationship to the virtual environment (Sweeney et al., 2015), many studies have shown that the use of a material for occlusal record in dentate patients changes the relative position of the maxillary and mandibular models, which can lead to incorrect positioning of virtual models (Solaberrieta et al., 2016; Solaberrieta et al., 2015; Iwaki et al., 2013; Wong et al., 2018). Furthermore, the most used materials such as wax and silicones undergo dimensional change over time, which can end up causing distortions on records (Solaberrieta et al., 2016; Wong et al., 2018). 
Virtual interocclusal record seems to show adequate accuracy when all teeth in the maxillary and mandibular arches are present and when at most one element is absent or does not have contact with the antagonist tooth (Ren et al., 2020; Iwaki et al., 2013). However, it is possible to note that when occlusal record of models with extensive edentulous space or with more than one element followed without contact with the antagonist is necessary, the virtual interocclusal record method suffers a significant reduction in its accuracy (Ren et al., 2020; Iwaki et al., 2013). Studies to assess the accuracy of the virtual record in cases where there are absences of dental elements are important. They enable the improvement of equipment and the development of techniques and tools capable of overcoming this limitation, enabling the use of a complete digital flow in all cases.

The literature does not yet define a gold standard for assessing the precision and accuracy of virtual occlusal records, as different studies use different forms of assessment that are not comparable with each other (Abdulateef et al., 2019; Iwaki et al., 2013; DeLong et al., 2007; Ren et al., 2020; Solaberrieta et al., 2015; Wong et al., 2018;). The consulted studies demonstrated two main forms of assessment of the accuracy and precision of virtual occlusal records. The first is through the quantitative and qualitative comparison of occlusal contacts (DeLong et al., 2007; Solaberrieta et al., 2015). The second way is through measuring the distance of pairs of reference points located in the maxillary and mandibular models (Ren et al., 2020; Iwaki et al., 2013). However, there are not many studies that correlate the two methods for evaluating virtual occlusal record with aspects of clinical accuracy, not clarifying which method is ideal to analyze this type of occlusal record.

\section{Final Considerations}

Despite the different recording techniques described and the different ways to assess their accuracy and precision, in general, studies show that virtual occlusal records of dentate models performed with the systems available today have adequate precision and accuracy. However, as the analyzes are performed with different methodologies, it is not possible to reach a consensus regarding the best way to assess the virtual occlusal relationship. In addition, the absence of dental elements represents a critical clinical situation related to the lower accuracy of virtual occlusal record, requiring further studies to define an appropriate technique for these cases.

\section{References}

Abdulateef, S., Edher, F., Hannam, A. G., Tobias, D. L., \& Wyatt, C. C. (2019). Clinical accuracy and reproducibility of virtual interocclusal records. The Journal of prosthetic dentistry, 124(6), 667-673.

Ahlholm, P., Sipilä, K., Vallittu, P., Jakonen, M., \& Kotiranta, U. (2018). Digital versus conventional impressions in fixed prosthodontics: a review. Journal of Prosthodontics, 27(1), 35-41.

Alghazzawi, T. F. (2016). Advancements in CAD/CAM technology: Options for practical implementation. Journal of prosthodontic research, 60(2), 72-84.

Batson, E. R., Cooper, L. F., Duqum, I., \& Mendonça, G. (2014). Clinical outcomes of three different crown systems with CAD/CAM technology. The Journal of prosthetic dentistry, 112(4), 770-777.

Botsford, K. P., Frazier, M. C., Ghoneima, A. A., Utreja, A., Bhamidipalli, S. S., \& Stewart, K. T. (2019). Precision of the virtual occlusal record. The Angle Orthodontist, 89(5), 751-757.

DeLong, R., Ko, C. C., Anderson, G. C., Hodges, J. S., \& Douglas, W. H. (2002). Comparing maximum intercuspal contacts of virtual dental patients and mounted dental casts. The Journal of prosthetic dentistry, 88(6), 622-630.

DeLong, R., Knorr, S., Anderson, G. C., Hodges, J., \& Pintado, M. R. (2007). Accuracy of contacts calculated from 3D images of occlusal surfaces. Journal of dentistry, 35(6), 528-534

Ender, A., Attin, T., \& Mehl, A. (2016). In vivo precision of conventional and digital methods of obtaining complete-arch dental impressions. The Journal of prosthetic dentistry, 115(3), 313-320

Ender, A., Zimmermann, M., Attin, T., \& Mehl, A. (2016). In vivo precision of conventional and digital methods for obtaining quadrant dental impressions. Clinical oral investigations, 20(7), 1495-1504. 
Research, Society and Development, v. 10, n. 14, e44101421507, 2021

(CC BY 4.0) | ISSN 2525-3409 | DOI: http://dx.doi.org/10.33448/rsd-v10i14.21507

Fang, Y., Fang, J. H., Jeong, S. M., \& Choi, B. H. (2019). A technique for digital impression and bite registration for a single edentulous arch. Journal of Prosthodontics, 28(2), e519-e523.

Iwaki, Y., Wakabayashi, N., \& Igarashi, Y. (2013). Dimensional accuracy of optical bite registration in single and multiple unit restorations. Operative dentistry, 38(3), 309-315.

Iwauchi, Y., Tanaka, S., Kamimura-Sugimura, E., \& Baba, K. (2021). Clinical evaluation of the precision of interocclusal registration by using digital and conventional techniques. The Journal of Prosthetic Dentistry.

Mangano, F., Gandolfi, A., Luongo, G., \& Logozzo, S. (2017). Intraoral scanners in dentistry: a review of the current literature. BMC oral health, 17(1), 1-11.

Nagarkar, S. R., Perdigao, J., Seong, W. J., \& Theis-Mahon, N. (2018). Digital versus conventional impressions for full-coverage restorations: A systematic review and meta-analysis. The Journal of the American Dental Association, 149(2), 139-147.

Park, J. M., Jeon, J., \& Heo, S. J. (2018). Accuracy comparison of buccal bite scans by five intra-oral scanners. Journal of Dental Rehabilitation and Applied Science, 34(1), 17-31.

Ren, S., Morton, D., \& Lin, W. S. (2020). Accuracy of virtual interocclusal records for partially edentulous patients. The Journal of prosthetic dentistry, 123(6), 860-865.

Rother, E.T. Revisão sistemática X revisão narrativa. (2007). Acta paul.enferm. v.20(2).

Russo, L. L., Caradonna, G., Biancardino, M., De Lillo, A., Troiano, G., \& Guida, L. (2019). Digital versus conventional workflow for the fabrication of multiunit fixed prostheses: A systematic review and meta-analysis of vertical marginal fit in controlled in vitro studies. The Journal of prosthetic dentistry, 122(5), 435-440.

Sailer, I., Mühlemann, S., Fehmer, V., Hämmerle, C. H., \& Benic, G. I. (2019). Randomized controlled clinical trial of digital and conventional workflows for the fabrication of zirconia-ceramic fixed partial dentures. Part I: Time efficiency of complete-arch digital scans versus conventional impressions. The Journal of prosthetic dentistry, 121(1), 69-75.

Seo, J. M., Oh, W. S., \& Lee, J. J. (2019). A technique for verifying the accuracy of the virtual mounting of digital scans against the actual occlusal contacts. The Journal of prosthetic dentistry, 121(5), 729-732.

Solaberrieta, E., Arias, A., Brizuela, A., Garikano, X., \& Pradies, G. (2016). Determining the requirements, section quantity, and dimension of the virtual occlusal record. The Journal of prosthetic dentistry, 115(1), 52-56.

Solaberrieta, E., Otegi, J. R., Goicoechea, N., Brizuela, A., \& Pradies, G. (2015). Comparison of a conventional and virtual occlusal record. The Journal of prosthetic dentistry, 114(1), 92-97.

Sweeney, S., Smith, D. K., \& Messersmith, M. (2015). Comparison of 5 types of interocclusal recording materials on the accuracy of articulation of digital models. American Journal of Orthodontics and Dentofacial Orthopedics, 148(2), 245-252.

Wong, K. Y., Esguerra, R. J., Chia, V. A. P., Tan, Y. H., \& Tan, K. B. C. (2018). Three-dimensional accuracy of digital static interocclusal registration by three intraoral scanner systems. Journal of Prosthodontics, 27(2), 120-128. 